\title{
Effects of a Cancer Prevention Advertisement on Beliefs and Knowledge about Cancer Prevention
}

\author{
Su Yeon Kye, Jisu Yoo, Min Hee Lee, Jae Kwan Jun*
}

\begin{abstract}
Background: Outcome-expectation beliefs and knowledge may ultimately influence behavior for cancer prevention. The aims of this study were to measure changes in knowledge and beliefs about cancer prevention before and after viewing a television advertisement and identify the factors affecting receptivity to its messages. Materials and Methods: A one-group pretest-posttest design was used in this study of 1,000 individuals aged 20 to 65 years who were recruited online in November 2014. The outcome variables included cancer prevention beliefs based on the Health Belief Model (five items) and knowledge about risk factors for cancer (seven items). Results: Perceived susceptibility, perceived benefits, and self-efficacy increased significantly and their perceived severity and perceived barriers decreased significantly, after participants viewed the television advertisement. Correct responses to questions about risk factors also increased significantly, except for smoking. The main factors affecting changes in the outcome variables were age, interest in cancer prevention, social network, satisfaction with the ad, and pretest scores. Conclusions: Television advertisements with positive frameworks can be an efficient channel of improving beliefs and knowledge about cancer prevention in a short period. The continuous development of intervention materials that consider the demographics, needs, and satisfaction of the target group will be necessary for future studies.
\end{abstract}

Keywords: Beliefs - knowledge - television advertisements - cancer prevention - Korea

Asian Pac J Cancer Prev, 16 (14), 5793-5800

\section{Introduction}

Approximately half of all cancer deaths can be prevented by the improvement of health behaviors and environmental factors (Peto, 2011). The most common risk factors for cancer associated with health behaviors include smoking, drinking, unhealthy diet, insufficient physical activity, infection, and not having cancer screenings. Health behavior is a function of one's subjective value of an outcome and of the subjective probability, or expectation, that a particular action will achieve that outcome (Champion, 2008). Outcome-expectation beliefs about cancer prevention may influence awareness, attitude, motivation, management, and behaviors related to cancer prevention, and thereby affect the onset of multiple diseases (Niederdeppe and Levy, 2007). Based on the hypothesis that improvements in beliefs and better adherence to preventive behaviors is preceded by information, we propose that increased knowledge of risk factors for cancer will play an essential role in cancer prevention (Oh, et al., 2013; Peltzer and Pengpid, 2014; Tasci-Duran et al., 2014).

Researchers have concluded that the readiness to take action can be potentiated by cues to instigate action, such as media publicity (Champion, 2008). The dissemination of information about cancer prevention through mass media may help to reduce the burden of cancer (Grunfeld et al., 2004). The public can be updated about cancer risks using mass media, and the media can affect the public's knowledge and beliefs about cancer by including a series of risk factors in prevention messages thereby improving viewers' motivation to take desired actions (Akhu-Zaheya et al., 2013). A nationwide representative survey in the US found that participants who had high levels of media exposure to health-related content showed an excellent level of knowledge about the causes of cancer (Kelly et al., 2009; Stryker et al., 2008). Several population-based studies revealed that television campaigns were effective in increasing the number of attempts to quit smoking in the general population and increasing the use of colon cancer screening (Cram et al., 2003; McAfee et al., 2013).

Television advertisements, one of the forms of mass media, constitute a major source of cues for practicing cancer prevention; however, there is a lack of evidence supporting the impact of television ads on viewers' knowledge and beliefs about cancer prevention. Previous studies on the effects of cancer-related ads have mainly focused on one particular health behavior, such as smoking cessation or cancer screening (Cram et al., 2003; Hanewinkel et al., 2010; Jenkins et al., 1999; Lee et al., 
2013). Additionally, only a few studies have examined which factors might affect changes in knowledge and beliefs about diseases, excluding cancer, over time; and few investigations have been conducted to determine the factors related to changes in outcome variables that are associated with ads about cancer (Lynch et al., 2006; Reavley \& Jorm, 2014). In this study, the aims were to measure changes in knowledge and beliefs about cancer prevention among Korean adults before and after viewing television ads that dealt comprehensively with cancer risk factors in an online experimental setting, and to identify the factors affecting their receptivity to the ad's messages. It was hypothesized that when participants were exposed to a television ad for cancer prevention, their level of knowledge about risk factors for cancer would increase, their beliefs about cancer prevention would show positive changes, and the patterns of changes would differ according to their socioeconomic and cancer-related characteristics.

\section{Materials and Methods}

\section{Study design}

A one-group pretest-posttest design was used for the online survey, which was conducted during a two-week period in November 2014. The effects of the experimental treatment were determined by comparing scores on the pretest and posttest measures.

\section{Intervention materials}

A40-second cancer prevention advertisement produced by the Ministry of Health and Welfare and the National Cancer Center titled, "I keep to keep." was used in the study. The script was initially written by an advertising agency and revised through a series of meetings with cancer and communication experts. The plot shows one family's issues related to cancer prevention practices over the life cycle: smoking cessation and limited drinking in their 20s, healthy diet in their 30s, physical activity and weight control in their 40s, and cancer screening in their 50s. The clip ends with subtitles "You keep the Cancer Prevention Codes to keep." The overall context was bright and positive and the messages emphasized the favorable outcome of conformity with cancer prevention practices.

\section{Participants and procedure}

The participants of this experimental study were recruited through online sampling. E-mails notifying potential recruits about participation in the survey were distributed to a nationwide panel of one research company-Gallup - and volunteers completed a set of measures. After the participants finished the baseline survey, they watched the cancer prevention advertisement and then answered posttest questions. Based on the multiple stratified sampling procedure used, which considered gender, age, and administrative districts, a total of 1,000 individuals between 20 and 65 years of age, with no history of cancer were chosen.

\section{Measures}

The set of questions was answered by participants two times: immediately before and immediately after watching the ad. Participants' beliefs about cancer prevention were measured by questions based on the Health Belief Model (HBM). The HBM contains several primary concepts that predict why people will take action to control illness conditions; these include severity, susceptibility, benefits, barriers, and self-efficacy (Champion, 2008). Participants' views about the severity of cancer were measured by asking them whether they agreed or disagreed with the statement, "When I think of cancer, I automatically think of death." Participants were asked how likely they thought that they would get cancer in the future in order to measure their perceived susceptibility. The following statement was used to determine the respondents' perceived benefits: "Cancer is an illness, that when detected early, can typically be cured." The perceived barriers for not being able to participate in cancer prevention behaviors were measured by asking participants if they agreed or disagreed with the following statement: "Because there are so many different recommendations about preventing cancer, it's hard to know which ones to follow." Selfefficacy was measured to rate the level of confidence in the participant's own ability to engage in cancer prevention behaviors. The ratings of the items on the scales ranged from 1 "definitely no" to 5 "definitely yes," and were based on previous studies (Choi et al., 2013; Davis et al., 2013; Sach and Whynes, 2009). Participants' responses were collapsed into two categories: high ("definitely yes" and "somewhat yes") and low ("definitely no," "somewhat no," and "moderate").

To measure the level of cancer-prevention knowledge, the current research team selected seven items based on the Cancer Prevention Codes, developed by the Korea National Cancer Center. The participants were asked to select "yes," "no," or "don't know" in response to whether they thought that each practice could protect people from cancer: not smoking, not drinking, avoiding obesity, engaging in physical activity, consuming fruits and vegetables, avoiding salty or burnt foods, and having cancer screening.

To identify the variables affecting the differences found after the intervention, questions about participants' demographics (gender, age, education, income, job, and marital status), medical characteristics (family cancer history), health-communication behaviors (lifetime cancer prevention information seeking), social contexts (social networks: the number of community organizations which one participated in, social support: whether one had family members or friends to talk with about health, and interest in cancer prevention), and satisfaction about the ad were included in the pretest questionnaire.

\section{Data analysis}

Cell percentages (\%) were calculated for the participants' characteristics. McNemar tests were used to examine the differences between pretest and posttest scores on the participants' beliefs and knowledge about cancer prevention. Multivariate logistic regression analyses were employed to identify the factors associated with differences in the beliefs and knowledge about cancer prevention, after adjusting for all of the variables. Data were analyzed using SPSS 15.0 software. 


\section{Results}

Characteristics of the participants

The proportion of male respondents was $50.9 \%$ and more than $70 \%$ were college graduates. Approximately $35 \%$ of the participants reported that their household income was over 5,000 US dollars per month. Approximately 3 out of 10 participants had family members with cancer; $20 \%$ had sought cancer-prevention information, and $64.8 \%$ were interested in cancer prevention. Approximately $23 \%$ had not participated in any community organization, while $13.7 \%$ were involved in more than four community organizations. Roughly half of the participants had family members or friends to talk with about health. The proportion of respondents who were satisfied with the intervention ad was $68.3 \%$.

Effects of the television ad on beliefs and knowledge about cancer prevention

The level of perceived severity decreased (pre: $78.6 \%$, post: $65.2 \%$ ) after watching the ad, while perceived susceptibility increased (pre: $28.8 \%$, post: $34.1 \%$ ). Participants were more likely to perceive the benefits of cancer-prevention practices after exposure to the ad (pre:

\section{Table 1. Comparison of Differences in the Beliefs and Knowledges about Cancer Prevention}

\begin{tabular}{|c|c|c|c|c|c|c|}
\hline & & \multicolumn{3}{|c|}{ Posttest } & \multirow[t]{2}{*}{$\chi^{2}$} & \multirow[t]{2}{*}{ p-valuea } \\
\hline & & Low/Incorrect & High/Correct & Total & & \\
\hline \multirow[t]{49}{*}{ Pretest } & Perceived severity & & & & & \\
\hline & Low & $168(78.5)$ & $46(21.5)$ & $214(21.4)$ & 229.2 & $<0.001$ \\
\hline & High & $180(22.9)$ & $606(77.1)$ & $786(78.6)$ & & \\
\hline & Total & $348(34.8)$ & $652(65.2)$ & $1000(100.0)$ & & \\
\hline & Perceived susceptibility & & & & & \\
\hline & Low & $576(80.9)$ & $136(19.1)$ & $712(71.2)$ & 247.49 & $<0.001$ \\
\hline & High & $83(28.8)$ & $205(71.2)$ & $288(28.8)$ & & \\
\hline & Total & $659(65.9)$ & $341(34.1)$ & $1000(100.0)$ & & \\
\hline & Perceived benefits & & & & & \\
\hline & Low & $117(48.0)$ & $127(52.0)$ & $244(24.4)$ & 164.62 & $<0.001$ \\
\hline & High & $79(10.4)$ & $677(89.6)$ & $756(75.6)$ & & \\
\hline & Total & $196(19.6)$ & $804(80.4)$ & $1000(100.0)$ & & \\
\hline & Perceived barriers & & & & & \\
\hline & Low & $62(63.3)$ & $36(36.7)$ & $98 \quad(9.8)$ & 62.44 & $<0.001$ \\
\hline & High & $227(25.2)$ & $675(74.8)$ & $902 \quad(90.2)$ & & \\
\hline & Total & $289(28.9)$ & $711(71.1)$ & $1000(100.0)$ & & \\
\hline & Self-efficacy & & & & & \\
\hline & Low & $352(51.1)$ & 337 (48.9) & 689 (68.9) & 75.12 & $<0.001$ \\
\hline & High & $68(21.9)$ & $243(78.1)$ & $311 \quad(31.1)$ & & \\
\hline & Total & $420(42.0)$ & $580(58.0)$ & $1000(100.0)$ & & \\
\hline & Knowledge about how $\mathrm{t}$ & & & & & \\
\hline & Not smoking & & & & & \\
\hline & Incorrect & $19(42.2)$ & $26(57.8)$ & $45 \quad(4.5)$ & 95.11 & 0.014 \\
\hline & Correct & $48 \quad(5.0)$ & $907(95.0)$ & $955(95.5)$ & & \\
\hline & Total & $67 \quad(6.7)$ & $933(93.3)$ & $1000(100.0)$ & & \\
\hline & Not drinking & & & & & \\
\hline & Incorrect & $67(42.1)$ & $92(57.9)$ & 159 (15.9) & 167.19 & 0.001 \\
\hline & Correct & $51 \quad(6.1)$ & $790(93.9)$ & $841 \quad(84.1)$ & & \\
\hline & Total & $118(11.8)$ & $882(88.2)$ & $1000(100.0)$ & & \\
\hline & Avoiding obesity & & & & & \\
\hline & Incorrect & $126(36.8)$ & $216(63.2)$ & 342 (34.2) & 132.69 & $<0.001$ \\
\hline & Correct & $50 \quad(7.6)$ & $608(92.4)$ & $658 \quad(65.8)$ & & \\
\hline & Total & $176(17.6)$ & $824(82.4)$ & $1000(100.0)$ & & \\
\hline & Engaging in physi & & & & & \\
\hline & Incorrect & $88(35.9)$ & $157(64.1)$ & $245 \quad(24.5)$ & 104.86 & $<0.001$ \\
\hline & Correct & $66(8.7)$ & $689(91.3)$ & $755 \quad(75.5)$ & & \\
\hline & Total & $154(15.4)$ & 846 (84.6) & $1000(100.0)$ & & \\
\hline & Consuming fruits & & & & & \\
\hline & Incorrect & $59(35.3)$ & $108(64.7)$ & 167 (16.7) & 108.35 & $<0.001$ \\
\hline & Correct & $58 \quad(7.0)$ & $775(93.0)$ & $833 \quad(83.3)$ & & \\
\hline & Total & $117(11.7)$ & $883(88.3)$ & $1000(100.0)$ & & \\
\hline & Avoiding salty or 1 & & & & & \\
\hline & Incorrect & $41(30.8)$ & $92(69.2)$ & 133 (13.3) & 76.72 & $<0.001$ \\
\hline & Correct & $57 \quad(6.6)$ & $810(93.4)$ & $867 \quad(86.7)$ & & \\
\hline & Total & $98 \quad(9.8)$ & $902(90.2)$ & $1000(100.0)$ & & \\
\hline & Having cancer scr & & & & & \\
\hline & Incorrect & $46(37.7)$ & $76(62.3)$ & $122(12.2)$ & 114.76 & $<0.001$ \\
\hline & Correct & $56 \quad(6.4)$ & $822(93.6)$ & $878 \quad(87.8)$ & & \\
\hline & Total & $102(10.2)$ & $898(89.8)$ & $1000(100.0)$ & & \\
\hline
\end{tabular}




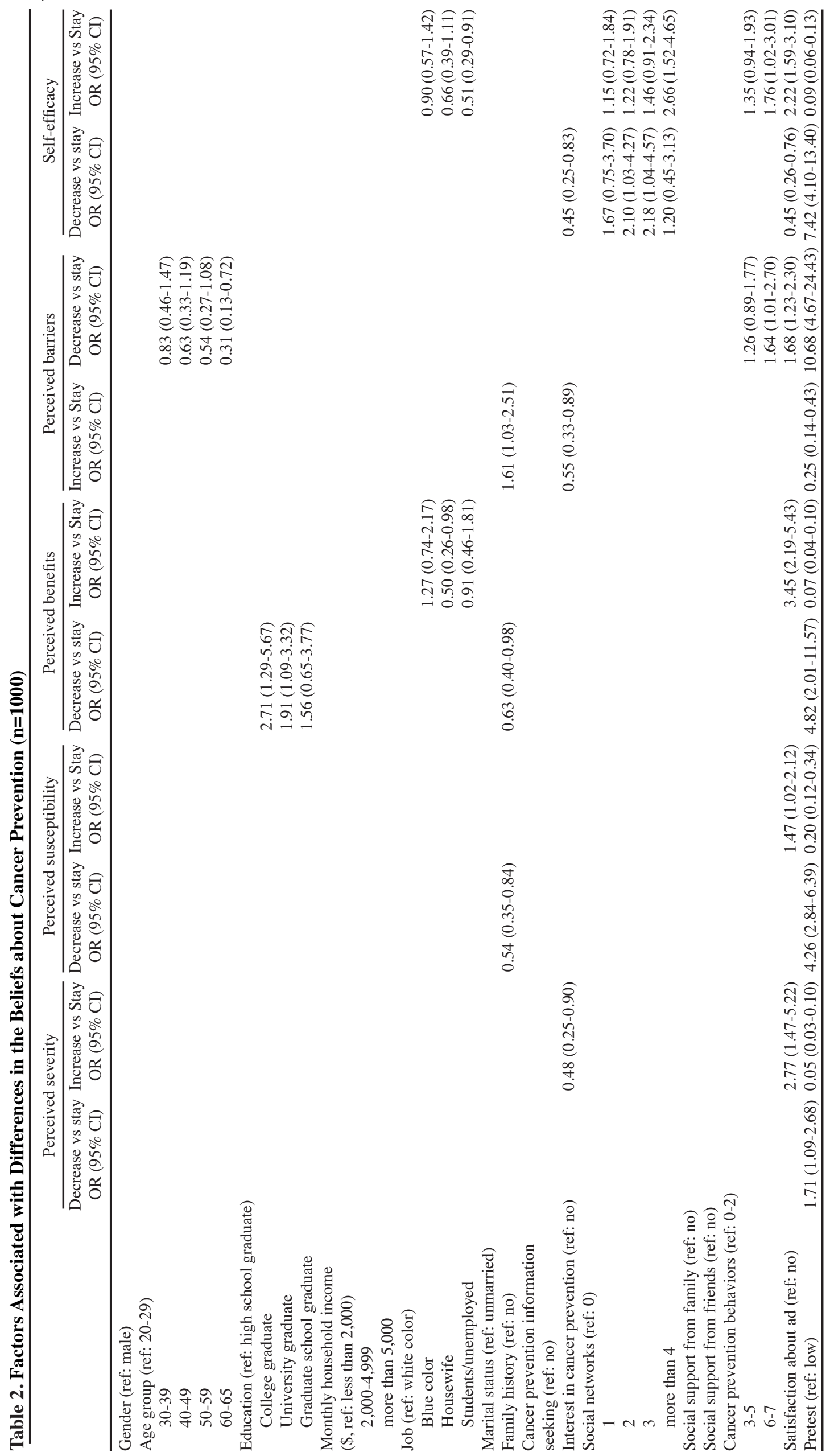

5796 Asian Pacific Journal of Cancer Prevention, Vol 16, 2015 
DOI:http://dx.doi.org/10.7314/APJCP.2015.16.14.5793

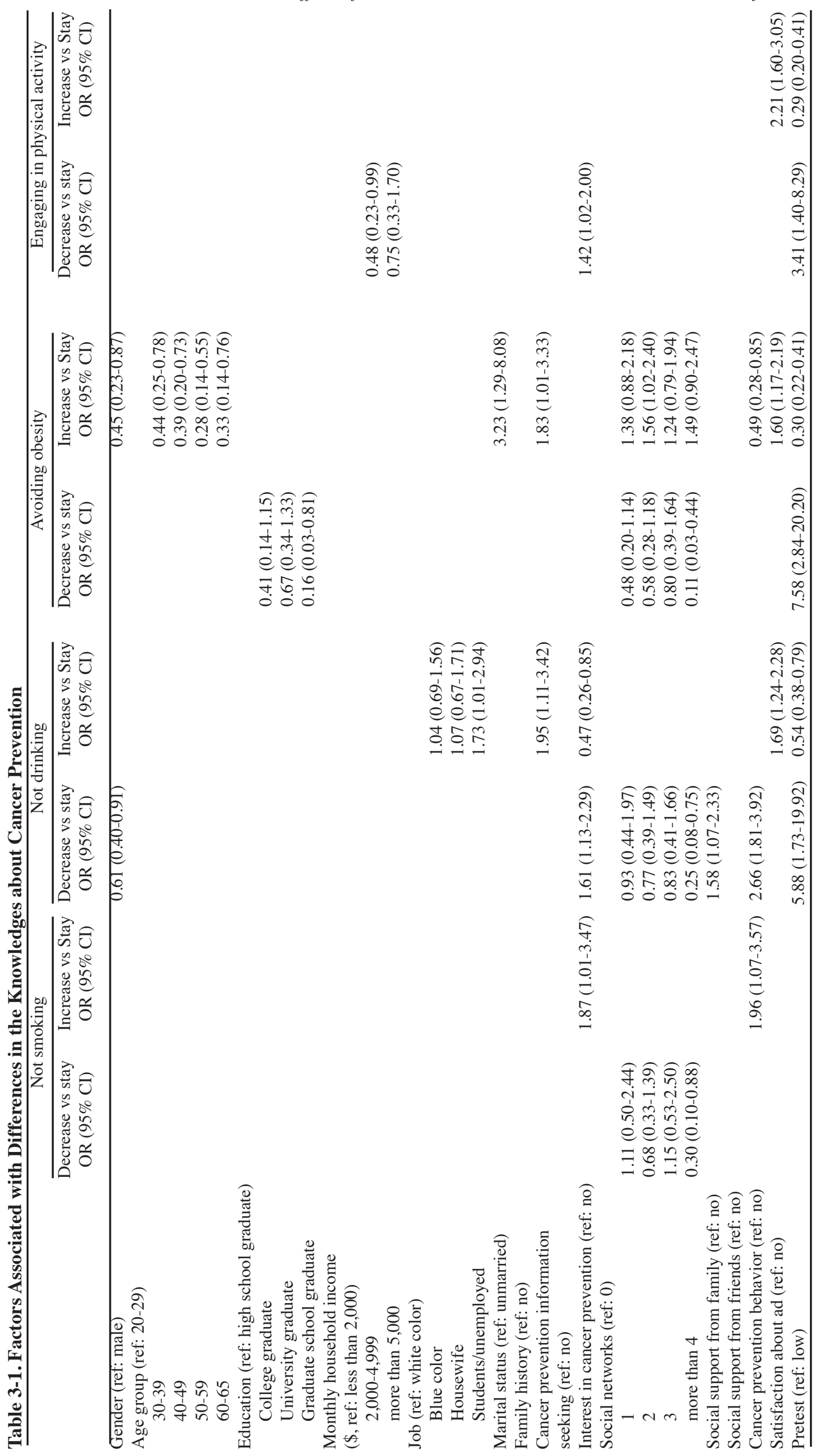

Effects of a Television Advertisement on Cancer Prevention Beliefs and Knowledge

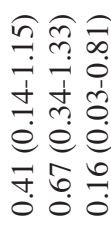

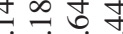

के के

èe

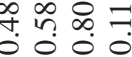

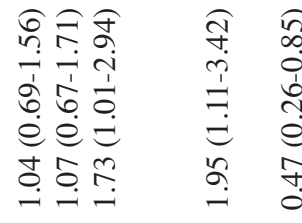

๙ิণ

ปุ

ât.

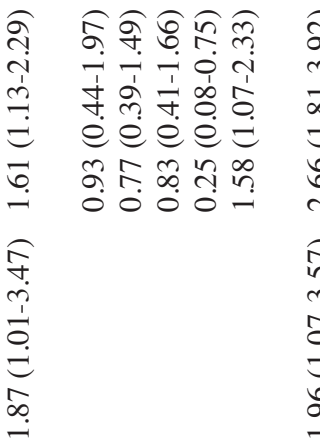

 
Su Yeon Kye et al

$75.6 \%$, post: $80.4 \%$ ), and were less likely to perceive the barriers (pre: $90.2 \%$, post: $71.1 \%$ ). The posttest showed that $58 \%$ of the respondents had confidence in their own ability to engage in cancer-prevention behaviors, while $31.1 \%$ had confidence at the pretest. The respondents who reported drinking, insufficient consumption of fruit and vegetables, eating salty or burnt foods, and not having cancer screening showed moderate increases in these risk factors for cancer (pre: 84.1\%, 83.3\%, 86.7\%, 87.8\%, post: $88.2 \%, 88.3 \%, 90.2 \%, 89.8 \%$ ), while the proportion of responses that reported smoking decreased (pre: $95.5 \%$, post: $93.3 \%$ ). The effect of the cancer prevention ad on improving knowledge was significantly larger for avoiding obesity and engaging in physical activity than for any of the other practices (pre: $65.8 \%, 75.5 \%$, post: $82.4 \%$, $84.6 \%$ ) (Table 1).

Factors related to changes in beliefs and knowledge

A series of multiple regression models of participants' beliefs before and after viewing ad revealed that a few of the independent variables were predictors of the dependent variables - changes in the beliefs and knowledge. The older participants were less likely to show a reduction in their perceived barriers after watching the ad. The respondents who were interested in cancer prevention were less likely to show an increase in their perceived barriers and a decrease in self-efficacy. The participants with healthier cancer-prevention habits were more likely to show a reduction in their perceived barriers and increase in selfefficacy after exposure to the ad. Participants' satisfaction with the ad and the pretest scores were significant predictors for all of the dependent variables. With regard to differences in knowledge, age was associated with changes in knowledge, indicating that older people were less likely to show increases in knowledge. The respondents who had sought cancer-prevention information were more likely to show decreased knowledge about not drinking, avoiding obesity, and eating fruits and vegetables. Interest in cancer prevention was positively associated with changes in knowledge about not smoking, avoiding obesity, eating fruits and vegetables, avoiding salty or burnt foods, and having cancer screening. Participants with many social networks were more likely to increase their knowledge about avoiding obesity, eating fruits and vegetables, avoiding salty or burnt foods, and having cancer screening, and they were less likely to show decreased knowledge about not smoking, not drinking, and avoiding obesity. Cancer-prevention behavior, satisfaction with the ad,

Table 3-2. Factors Associated with Differences in the Knowledges about Cancer Prevention (Cont.)

\begin{tabular}{|c|c|c|c|c|c|c|}
\hline & \multicolumn{2}{|c|}{ Consuming fruits and vegetables } & \multicolumn{2}{|c|}{ Avoiding salty or burnt foods } & \multicolumn{2}{|c|}{ Having cancer screening } \\
\hline & $\begin{array}{l}\text { Decrease vs stay } \\
\text { OR }(95 \% \text { CI })\end{array}$ & $\begin{array}{c}\text { Increase vs Stay } \\
\text { OR }(95 \% \text { CI })\end{array}$ & $\begin{array}{l}\text { Decrease vs stay } \\
\text { OR }(95 \% \mathrm{CI})\end{array}$ & $\begin{array}{c}\text { Increase vs Stay } \\
\text { OR }(95 \% \text { CI })\end{array}$ & $\begin{array}{c}\text { Decrease vs stay } \\
\text { OR }(95 \% \text { CI })\end{array}$ & $\begin{array}{c}\text { Increase vs Stay } \\
\text { OR }(95 \% \text { CI })\end{array}$ \\
\hline Gender (ref: male) & & & $1.57(1.12-2.18)$ & & & $1.88(1.18-2.97)$ \\
\hline \multicolumn{7}{|l|}{ Age group (ref: 20-29) } \\
\hline $30-39$ & & & & $0.71(0.40-1.27)$ & & $0.61(0.33-1.10)$ \\
\hline $40-49$ & & & & $0.79(0.42-1.49)$ & & $0.43(0.22-0.83)$ \\
\hline $50-59$ & & & & $0.48(0.24-0.96)$ & & $0.39(0.19-0.80)$ \\
\hline $60-65$ & & & & $0.62(0.27-1.44)$ & & $0.31(0.13-0.74)$ \\
\hline \multicolumn{7}{|c|}{ Education (ref: high school graduate) } \\
\hline College graduate & & & $0.47(0.20-1.13)$ & $0.78(0.46-1.32)$ & & \\
\hline University graduate & & & $0.70(0.39-1.26)$ & $0.87(0.59-1.28)$ & & \\
\hline Graduate school graduate & & & $0.35(0.12-0.97)$ & $0.41(0.21-0.77)$ & & \\
\hline \multirow{2}{*}{\multicolumn{7}{|c|}{$\begin{array}{l}\text { Monthly household income } \\
(\$, \text { ref: less than } 2,000)\end{array}$}} \\
\hline & & & & & & \\
\hline \multicolumn{7}{|l|}{ 2,000-4,999 } \\
\hline more than 5,000 & & & & & & \\
\hline \multicolumn{7}{|l|}{ Job (ref: white color) } \\
\hline Blue color & $1.00(0.51-1.95)$ & & $0.69(0.35-1.36)$ & & $0.66(0.35-1.24)$ & \\
\hline Housewife & $0.29(0.11-0.72)$ & & $0.39(0.16-0.91)$ & & $0.25(0.12-0.55)$ & \\
\hline Students/unemployed & $1.32(0.59-2.95)$ & & $0.72(0.32-1.60)$ & & $1.11(0.49-2.53)$ & \\
\hline Marital status (ref: unmarried) & & & & & & $2.15(1.08-4.26)$ \\
\hline \multicolumn{7}{|l|}{ Family history (ref: no) } \\
\hline $\begin{array}{l}\text { Cancer prevention information } \\
\text { seeking (ref: no) }\end{array}$ & & $2.20(1.33-3.63)$ & & & & \\
\hline $\begin{array}{l}\text { Interest in cancer prevention } \\
\text { (ref: no) }\end{array}$ & & $1.45(1.04-2.03)$ & & $1.80(1.29-2.52)$ & & $1.44(1.02-2.03)$ \\
\hline \multicolumn{7}{|l|}{ Social networks (ref: 0) } \\
\hline 1 & & $1.66(1.04-2.64)$ & & $1.54(0.97-2.43)$ & & $1.51(0.95-2.40)$ \\
\hline 2 & & $1.45(0.95-2.23)$ & & $1.12(0.74-1.70)$ & & $1.15(0.75-1.76)$ \\
\hline 3 & & $1.59(1.02-2.48)$ & & $1.83(1.17-2.87)$ & & $1.58(1.01-2.49)$ \\
\hline more than 4 & & $1.39(0.83-2.32)$ & & $1.95(1.16-3.28)$ & & $1.50(0.88-2.54)$ \\
\hline $\begin{array}{l}\text { Social support from family } \\
\text { (ref: no) }\end{array}$ & & $1.83(1.04-3.22)$ & & & & \\
\hline \multicolumn{7}{|l|}{$\begin{array}{l}\text { Social support from friends } \\
\text { (ref: no) }\end{array}$} \\
\hline $\begin{array}{l}\text { Cancer prevention behavior } \\
\text { (ref: no) }\end{array}$ & & & & $1.51(1.11-2.04)$ & & $1.53(1.03-2.26)$ \\
\hline Satisfaction about ad (ref: no) & & & $2.18(1.58-3.00)$ & $1.80(1.31-2.48)$ & & $2.14(1.55-2.95)$ \\
\hline Pretest (ref: low) & $4.90(1.45-16.48)$ & $0.30(0.20-0.45)$ & $6.17(1.41-27.06)$ & $0.33(0.21-0.52)$ & $3.28(1.22-8.83)$ & $0.50(0.32-0.78)$ \\
\hline
\end{tabular}


and the level of pretest scores were significant predictors of changes in overall knowledge (Table 2) (Table 3-1) (Table 3-2).

\section{Discussion}

The results of this study supported the hypothesis that participants' beliefs about cancer prevention and their level of knowledge about risk factors for cancer would increase after seeing a television ad for cancer prevention, and that changes in their beliefs and knowledge before and after the intervention would vary in accordance with certain variables. Perceived susceptibility, perceived benefits, and self-efficacy increased significantly, and perceived severity and perceived barriers decreased significantly, after viewing the television ad. Correct responses to questions about risk factors, except for smoking, also increased significantly. The main factors affecting the changes in the outcome variables were age, interest in cancer prevention, social network, satisfaction about the ad, and pretest scores.

Participants' perceived severity and perceived susceptibility were approximately $80 \%$ and $30 \%$, respectively, which implied that the fear of cancer among the participants in this study was higher than that reported in a study conducted in another developed country $(60 \%$ versus 20\%) (Davis et al., 2013). Our participants' perception of barriers was higher $(90 \%)$ and their level of self-efficacy $(31 \%)$ was much lower than those of the participants of the other country $(70 \%, 60 \%)$, whereas their levels of perceived benefits were similar $(75 \%)$ (Davis et al., 2013). The participants' awareness of risk factors, such as smoking (95.5\%), drinking (84.1\%), insufficient consumption of fruit and vegetables $(83.3 \%)$, and not undergoing cancer screening $(87.8 \%)$, was high but their knowledge about obesity $(65.8 \%)$ and lack of physical activity (75.5\%) was low. Several studies conducted in the UK during the 1990s also revealed that smoking and drinking were well-known as causes of cancer; however, obesity and lack of physical activity were less known to the public (Knowles and Hamilton, 2008; Sach and Whynes, 2009).

Participants' differences in their beliefs and knowledge between the times before and after the intervention, indicated that the fear of cancer and perceived barriers decreased and that perceived benefits and self-efficacy increased after the intervention. The reason seems to be that the television ad used a bright and positive framework to describe the cancer-prevention practices in detail, thereby raising the favorable outcome expectancy. Their overall knowledge of cancer risk factors improved, except for smoking, which was already at a high level. Therefore, the findings suggest the effectiveness of cancer communication through television ads emphasizing the heartfelt imagery with family-centered issues to raise the awareness of cancer prevention and the recognition of cancer risk factors. Previous studies also have confirmed that a media-led educational intervention was successful in promoting the recognition of, and intention to have cancer screening, suggesting the positive effect of television ads (Jenkins et al., 1999).
This study investigated the factors affecting changes in beliefs and knowledge after an intervention using a television ad. The magnitude of the decrease in perceived susceptibility was significantly smaller among the respondents with a family history of cancer, which was consistent with the results of a previous study of UK adults who perceived themselves as unhealthy and showed high levels of perceived susceptibility (Sach and Whynes, 2009). Age was a significant predictor of changes in perceived barriers. Respondents who were over sixty years of age, showed a smaller reduction in perceived obstacles for cancer-preventive practices. The Health Information National Trends Survey in the USA also found that older age was significantly associated with a higher perception of barriers (Niederdeppe and Levy, 2007). For this reason, further channels beyond television ads need to be developed to communicate effectively with the aging population to help them understand the message more easily. Because interest in cancer prevention was significantly related to the reduction in the magnitude of the increase in perceived barriers and a decrease in self-efficacy, information about varied issues addressing their needs for cancer prevention should be distributed. Additionally, participants' satisfaction about the ad and their pretest scores influenced the intervention's effects on their overall beliefs. High pretest scores were negatively associated with differences between the periods before and after the intervention, which might be due to a "ceiling effect." The respondents who expressed satisfaction about the ad showed favorable changes with regard to cancer prevention, which was consistent with the findings of previous studies (Heisig et al., 2015). In light of these associations, it is essential to create intervention materials based on the needs of the target group.

Our results showed that older age was negatively associated with the magnitude of the increase in knowledge about obesity, salty or burnt foods, and cancer screening. It was interesting that the knowledge levels of the respondents who sought information about cancer prevention decreased at the posttest, which was contrary to previous findings (Kye et al., 2010). This finding may shed light on further studies on the characteristics of cancer-prevention information seekers i.e., the content and type of information, and their trust in, and satisfaction with the information which they obtained. In this study, the number of social networks was positively related to improvements in participants' knowledge of risk factors, except for physical activity. Previous studies suggest that social contacts can influence a variety of cancer preventive behaviors (Christakis and Fowler, 2008; Rosenquist et al., 2010). Social networks have the potential to provide information about the necessity, benefits, and methods of practicing target behaviors that specifically prevent cancer. However, online social networks were not included in this study, although the number of social network services have increased dramatically in recent years. Similar to the results concerning beliefs, participants' interest in cancer prevention, satisfaction with the ad, and their pretest scores were significantly associated with increases in overall knowledge. These findings highlight the necessity to develop and implement communication strategies to raise 
the public's attention to cancer prevention and to produce intervention materials to fulfill these goals. Although knowledge about avoiding obesity and engaging in physical activity showed the most improvement, it was rare to find factors that predicted changes in knowledge about physical activity. This might be due to the limited number of variables that were included in the study. Previous investigations have found that physical environment was an important determinant of physical activity, indicating that the inclusion of physical and environmental variables is needed in future studies (Kye and Park, 2012).

Our findings should be interpreted in light of some limitations. The major limitation lies in the design of the study, which did not include a control group and had a short intervention period. For this reason, participants might have shown improvements simply as an effect of their exposure to the pretest. In addition, the use of the online survey method is not representative of Korean surveys, and therefore, our results are not generalizable. Because the outcome variables were restricted to cognitive measures, which represent the initial stages of the behavior change process, and because the intervention was not implemented in a real setting, we cannot assure others of the effectiveness of campaigns using television ads to promote the ultimate goal - behavior change - in real life. Future studies with a longer study period and a randomized control group in a real situation may help disentangle this problem.

In conclusion, The present study suggests that television ads with a positive framework can be an efficient channel to improve beliefs and knowledge about cancer prevention within a short period in spite of several limitations. In light of these findings, the use of supplementary channels and easily understood content, considering the health literacy of older men in Korea, will help the aged to accept health messages. Various issues to ignite the public's interest in cancer prevention should be developed and distributed through multiple channels. In addition, media producers need to develop communication materials to satisfy the expectations of the target group. To support these plans, it will be essential to develop a monitoring system to identify and evaluate Korean adults' patterns of utilization of cancer information, as both a producer and consumer.

\section{References}

Akhu-Zaheya LM, Jagbir MT, Othman A, Ahram M (2013). Media use for seeking health/cancer-related information: Findings from knowledge, attitudes and practices towards cancer prevention and care survey in Jordan. Int J Nurs Pract.

Champion VL, Skinner CS (2008). The health belief model. In 'Health behavior and health education', Eds Glanz K, Rimer BK, Viswanath K. Jossey-bass, San Francisco, USA p46.

Choi JH, Chung KM, Park K (2013). Psychosocial predictors of four health-promoting behaviors for cancer prevention using the stage of change of Transtheoretical Model. Psychooncology, doi: 10.1002/pon.3278.

Christakis NA, Fowler JH (2008). The collective dynamics of smoking in a large social network. N Engl J Med, 358, 2249-58.

Cram P, Fendrick AM, Inadomi J, et al (2003). The impact of a celebrity promotional campaign on the use of colon cancer screening: the Katie Couric effect. Arch Intern Med, 163, 1601-5.
Davis JL, Buchanan KL, Green BL (2013). Racial/ethnic differences in cancer prevention beliefs: applying the health belief model framework. Am J Health Promot, 27, 384-9.

Grunfeld E, Zitzelsberger L, Evans WK, Cameron R, Hayter C, Berman N, Stern H (2004). Better knowledge translation for effective cancer control: a priority for action. Cancer Causes Control, 15, 503-10.

Hanewinkel R, Isensee B, Sargent JD, Morgenstern M (2010). Effect of an antismoking advertisement on cinema patrons' perception of smoking and intention to smoke: a quasiexperimental study. Addiction, 105, 1269-77.

Heisig SR, Shedden-Mora MC, von Blanckenburg P, et al (2015). Informing women with breast cancer about endocrine therapy: effects on knowledge and adherence. Psychooncology, 24, 130-7.

Jenkins CN, McPhee SJ, Bird JA, et al (1999). Effect of a media-led education campaign on breast and cervical cancer screening among Vietnamese-American women. Prev Med, 28, 395-406.

Kelly BJ, Leader AE, Mittermaier DJ, Hornik RC, Cappella JN (2009). The HPV vaccine and the media: how has the topic been covered and what are the effects on knowledge about the virus and cervical cancer? Patient Educ Couns, 77, 308-13.

Knowles J, Hamilton W (2008). Knowledge of risk factors in cancer. Br J Gen Pract, 58, 650-1.

Kye SY, Cho J, Noh HI, Kwak MS, Chang YJ (2010). What types of cancer screening information are needed? Asian Pac $J$ Cancer Prev, 11, 607-13.

Kye SY, Park K (2012). Psychosocial factors and health behavior among Korean adults: a cross-sectional study. Asian Pac J Cancer Prev, 13, 49-56.

Lee S, Cappella JN, Lerman C, Strasser AA (2013). Effects of smoking cues and argument strength of antismoking advertisements on former smokers' self-efficacy, attitude, and intention to refrain from smoking. Nicotine Tob Res, $\mathbf{1 5}$, 527-33.

Lynch EB, Liu K, Kiefe CI, Greenland P (2006). Cardiovascular disease risk factor knowledge in young adults and 10-year change in risk factors: the Coronary Artery Risk Development in Young Adults (CARDIA) Study. Am J Epidemiol, 164, 1171-79.

McAfee T, Davis KC, Alexander RL, Pechacek TF, Bunnell R (2013). Effect of the first federally funded US antismoking national media campaign. Lancet, 382, 2003-11.

Niederdeppe J, Levy AG (2007). Fatalistic beliefs about cancer prevention and three prevention behaviors. Cancer Epidemiol Biomarkers Prev, 16, 998-1003.

Oh KM, Kreps GL, Jun J (2013). Colorectal cancer screening knowledge, beliefs, and practices of Korean Americans. Am $J$ Health Behav, 37, 381-94.

Peltzer K, Pengpid S (2014). Tobacco use, beliefs and risk awareness in university students from 24 low, middle and emerging economy countries. Asian Pac J Cancer Prev, 15, 10038-44.

Peto R (2011). The fraction of cancer attributable to lifestyle and environmental factors in the UK in 2010. Br J Cancer, 105.

Reavley NJ, Jorm AF (2014). The Australian publics beliefs about the causes of schizophrenia: associated factors and change over 16 years. Psychiatry Res, 220, 609-14.

Rosenquist JN, Murabito J, Fowler JH, Christakis NA (2010). The spread of alcohol consumption behavior in a large social network. Ann Intern Med, 152, 426-33.

Sach TH, Whynes DK (2009). Men and women: beliefs about cancer and about screening. BMC Public Health, 9, 431.

Stryker JE, Moriarty CM, Jensen JD (2008). Effects of newspaper coverage on public knowledge about modifiable cancer risks. Health Commun, 23, 380-390.

Tasci-Duran E, Koc S, Korkmaz M (2014). Turkish social attitudes towards to cancer prevention: a health belief model study. Asian Pac J Cancer Prev, 15, 7935-40. 